\title{
СТРАТЕГИИ ЦИФРОВИЗАЦИИ ПОЛИКУЛЬТУРНОЙ СРЕДЫ ВУЗА В УСЛОВИЯХ VUСА
}

\section{DIGITAL STRATEGIES OF UNIVERSITY POLYCULTURAL ENVIRONMENT UNDER VUCA}

\section{Ivanova}

Summary: The article provides analytical data on studies of the digitalization problem of the multicultural environment of the university, identifies its problem fields and the main challenges in the VUCA environment. The author offers a priority digitalization strategy for the multicultural environment of the university, which consists in developing its conceptual framework based on a comprehensive analysis of its structure and filling according to the criterion of homogeneity / heterogeneity and implementing a set of methods and algorithms for the dynamic adaptation of the multicultural environment of the university to the individual characteristics of students through its digitalization. The article also describes the possible options for implementing this strategy.

Keywords: environment, multicultural environment, multicultural environment of the university, digitalization, digitalization of the multicultural environment of the university, VUCA.

\author{
Иванова Лариса Владимировна, \\ К.и.н., дочент, Дальневосточный Государственный \\ Университет Путей Сообщения \\ professor.larisa.ivanova@gmail.com
}

Аннотация: В статье приводятся аналитические данные по исследованиям проблемы цифровизации поликультурной среды вуза, определяются ее проблемные поля и основные вызовы в условиях VUCA. Автор предлагает приоритетную стратегию цифровизации поликультурной среды вуза, заключающуюся в разработке ее концептуальных основ на основе проведения всестороннего анализа ее структуры и наполнения по критерию гомогенности / гетерогенности и реализации комплекса методов и алгоритмов динамической адаптации поликультурной среды вуза под индивидуальные особенности студентов путем ее цифровизации. В статье также описываются возможные варианты реализации данной стратегии.

Ключевые слова: среда, поликультурная среда, поликультурная среда вуза, цифровизация, цифровизация поликультурной среды вуза, VUCA.
$\mathrm{O}$ сновными вызовами современности по отношению к системе высшего образования являются требования к ее инновационному научному и образовательному потенциалу, значимости высшего образования для прогрессивного развития страны и ее высоким позициям на международном уровне. Система образования, как никакая другая общественная или социальная система, рефлектирует все социально-политические и экономические изменения, происходящие в обществе, поскольку именно от качества подготовки будущих специалистов зависит ее будущее, в том числе формат ее существования на мировой арене.

Основные тенденции модификации современной образовательной среды детерминированы среди прочих факторов интеграционными процессами, которые являются источником кардинальных изменений в современном мире и активно влияют на систему высшего образования. Формируется открытое мировое пространство, выражающееся в гармонизации образовательных стандартов в разных странах мира. Важный сегмент в данном процессе занимает трансформация форм и методов образовательной деятельности с учетом внедрения инновационных цифровых технологий и персонификации образовательных услуг [5]. Понятие VUCA, по мнению многих исследователей, наиболее точно описывает всю сложность ситуации в развивающейся и динамичной среде, в которой находится глобальное высшее образование на сегодняшний день [2; 6].

Актуальность рассматриваемой проблемы объясняется стремительно развертывающейся диверсификацией высшего образования, которая повышает востребованность выработки общих целей. Важное значение имеют при этом процесс глобализации профессий и усиление спроса на выпускников вузов, подготовленных к деятельности в мультикультурной среде и транснациональных корпорациях. Профессионально ориентированное высшее образование рассматривают в связи с этим с точки зрения практики профессии и академической мобильности будущих специалистов в поликультурном и полиязычном мире.

VUCA детерминирует хаотичную, турбулентную и быстро меняющуюся образовательную среду, которая является новой нормой в глобальном высшем образовании и требует от вузов прогнозирования, адаптации и быстрой реакции на изменения путем создания эффективных стратегий и практик образовательной деятельности.

Научный дискурс современных исследований инте- 
ресующего нас направления может быть условно представлен в следующих сегментах:

1 сегмент - исследования, посвященные поликультурной среде.

А.Л. Арефьев, Ю.В. Ломакина, И.В. Слесаренко, Ф.Э. Шереги и др. в своих исследованиях описывают содержательно-смысловое и функциональное наполнение поликультурной среды вуза и доказывают важную роль иностранного языка, который в случае использования в научно-образовательной среде отдельного вуза среди российских и зарубежных преподавателей, ученых и студентов является ключевым фактором формирования уникальной системы - поликультурной языковой среды, способствующей решению многих задач - превращению университета в центр международного образования и академических обменов.

2 сегмент - исследования, посвященные цифровизации образовательной деятельности вуза.

В работах Й. Виссемы, С.Г. Евсюкова [3], В.С. Ефимова [4], Т.В. Никулиной [7], Е.Б. Стариченко, Е.В. Устюжаниной и др. дефинируется понятие «цифровизация», а также описывается специфика процесса цифровизации образовательной деятельности вуза, в частности указывается, что цифровые технологии позиционируются не только как инструмент, но и как среда существования, которая открывает новые возможности: обучение в любое удобное время, непрерывное образование, возможность проектировать индивидуальные образовательные маршруты и т.п.

3 сегмент - исследования, посвященные цифровизации поликультурной среды вуза. Исследования данного направления посвящены разработке проблем, касающихся: 1) перевода имеющихся учебных материалов, в том числе лекций, презентаций, учебников, заданий для самостоятельной работы и инструментов контроля знаний, в электронную среду (Т.В. Никулина, Е.Б. Стариченко [7] и др.); 2) формирования интерактивной электронной среды взаимодействия педагога и обучающихся, в том числе создание электронных кабинетов преподавателей, проведение вебинаров, дискуссионных форумов и т.п.(Ю.И. Богатырева, М.Н. Лазарева, А.В. Якушин и др.); 3) создания новых типов учебных инструментов: электронных учебников, электронных задачников, видеолекций, квестов, компьютерных игр (А.В. Андреев, Т.В. Захарова, М.Н. Яковлева и др.); 4) создания принципиально новых форм обучения за счет использования возможностей электронной среды - расширения спектра образной передачи информации, моделирования различных ситуаций в ходе проведения ролевых игр, имитации состязательных игр и т.д. (О.И. Ребрин, Е.С. Фурсова, О.В. Штеймарк [8] и др.).
Анализ данных исследований доказывает, что особое значение имеет на современном этапе развития общества с учетом условий VUCA необходимость оптимизации образовательной деятельности вуза в аспекте переструктуризации его поликультурной среды и ее цифровизации, что включает в себя анализ специфики ее наполнения и функционирования, выделение проблемных полей и поиск и внедрение инновационных цифровых технологий с целью эффективной персонификации образовательного процесса, т.е. разработка соответствующих стратегий [1, с. 8].

Стратегии цифровизации поликультурной среды вуза, рассматриваемой как обстоятельства реализации образовательного процесса, в котором участвуют представители разных лингвокультур, должны разрабатываться с учетом специфики VUCA и основных вызовов, связанных с:

- в основном стихийным характером функционирования поликультурной среды вуза, связанным с отсутствием системного учета особенностей индивидуально-личностных и культурных характеристик студентов - иностранных граждан и студентов, владеющих несколькими иностранными языками или изучающих их;

- не в полной мере реализованными возможностями использования цифровых технологий и онлайн-курсов для обучения студентов в поликультурной среде вуза;

- недостаточным уровнем реализации возможностей виртуальной академической мобильности студентов в процессе изучения вузовских дисциплин.

Одной из приоритетных стратегий цифровизации поликультурной среды вуза в условиях VUCA является, на наш взгляд, разработка ее концептуальных основ на основе проведения всестороннего анализа ее структуры и наполнения по критерию гомогенности / гетерогенности и реализации комплекса методов и алгоритмов динамической адаптации поликультурной среды вуза под индивидуальные особенности студентов путем ее цифровизации.

Основными вариантами реализации данной стратегии являются следующие:

- системный учет особенностей индивидуальноличностных и культурных характеристик студентов - иностранных граждан и студентов, владеющих несколькими иностранными языками или изучающих их;

- анализ специфики поликультурной среды вуза и основных факторов, оказывающих негативное влияние на качество образовательного процесса в данной среде;

- выявление эффективных методов динамической 
адаптации поликультурной среды вуза под индивидуальные особенности студентов путем ее цифровизации;

- систематизация электронного образовательного контента с учетом специфики поликультурной среды вуза;

- использование онлайн-технологий и тьюторской поддержки студентов в процессе преподавания иностранных языков и культур;

- цифровизация поликультурной среды вуза для обеспечения виртуальной академической мобильности студентов.

Возможными стратегиями также могут быть следующие:

1. описание основных тенденций развития полилингвального и поликультурного образования средствами мультиязыковой среды обучения и интерактивных форм обучения;

2. разработка комплекса методов и алгоритмов динамической адаптации поликультурной среды вуза под индивидуальные особенности студентов путем ее цифровизации;

3. создание прогностической модели дистрибуции и систематизации электронного образовательного контента с учетом специфики поликультурной среды вуза;

4. разработка и комплексное описание оптималь- ных моделей использования онлайн-технологий и тьюторской поддержки студентов в процессе преподавания иностранных языков и культур;

5. описание возможностей цифровизации поликультурной среды вуза для обеспечения виртуальной академической мобильности студентов и построения индивидуальной траектории обучения с целью его персонификации;

6. разработка модели «смешанного обучения» (blended learning) с использованием онлай-технологий в процессе поликультурного и полиязычного образования студентов;

7. разработка программ виртуальной академической мобильности студентов;

8. разработка проекта единой кластерной модели методического обеспечения цифровизации поликультурной среды вуза.

Итак, полисегментарное моделирование процесса цифровизации поликультурной среды вуза в условиях VUCA предполагает, в первую очередь, разработку флагманской стратегии и подстратегий, связанных с разработкой ее концептуальных основ на основе проведения всестороннего анализа ее структуры и наполнения и реализацией комплекса методов и алгоритмов динамической адаптации поликультурной среды вуза под индивидуальные особенности студентов путем ее цифровизации.

\section{ЛИТЕРАТУРА}

1. Арчакова С.Ю. Управление инновационной средой в условиях цифровой экономики : автореферат дис. ... кандидата экономических наук : 08.00 .05 / Арчакова Светлана Юрьевна; [Место защиты: Воронеж. гос. техн. ун-т]. - Воронеж, 2019. - 23 с.

2. Глобальное высшее образование в мире VUCA: проблемы и перспективы [Электронный ресурс]. - Режим доступа: https://doi.org/10.20849/jed.v3i2.613 (дата обращения: 25.03.2020).

3. Евсюков С.Г., Устюжанина Е.В. Цифровизация образовательной среды: возможности и угрозы // Вестник РЭУ им. Г. В. Плеханова, 2018. - 1 (97). - С. 3-12.

4. Ефимов В.С., Лаптева А.В. Цифровизация в системе приоритетов развития российских университетов: экспертный взгляд. Университетское управление: практика и анализ. 2018;22(4):52-67. [Электронный ресурс]. - Режим доступа: https://doi.org/10.15826/umpa.2018.04.040 (дата 0бращения: 25.03.2020).

5. Кудинов В.А. Построение информационной образовательной среды вуза на основе технологий управления знаниями: диссертация... доктора педагогических наук: 13.00 .02 / В. А. Кудинов. - М., 2010. - 519 с.

6. Мир VUCA и подходы выживания в нем [Электронный ресурс]. - Режим доступа: http://becmology.ru/blog/management/vuca.htm (дата обращения: 25.03.2020).

7. Никулина Т.В., Стариченко Е.Б. Информатизация и цифровизация образования: понятия, технологии, управление // Педагогическое образование в России, 2018. - № 8. - С. 107-113.

8. Штеймарк 0.В. Повышение качества знаний студентов педагогического вуза средствами цифровых образовательных ресурсов: диссертация ... кандидата педагогических наук : 13.00.01 / Штеймарк Ольга Валентиновна; [Место защиты: Моск. гор. пед. ун-т].- Москва, 2011.- 178 с. 